\title{
Commentary: It is safe, but is it really better?
}

\author{
Donald D. Glower, MD
}

Lee and colleagues ${ }^{1}$ present a retrospective comparison of del Nido (DN) versus histidine-tryptophan-ketoglutarate (HTK) cardioplegia in 456 propensity-matched patients undergoing minimally invasive cardiac surgery (MICS), usually with single cardioplegia dosing. The authors conclude that, in comparison with HTK solution, DN solution seems to have acceptable safety and efficacy with more favorable myocardial protection in MICS. ${ }^{1}$

This is the only clinical trial in adults or minimally invasive surgery comparing HTK and DN solutions. The study is large and well powered with detailed findings. However, this study does have limitations. First, it is a retrospective, nonrandomized trial. Surgeon, time, and practice biases may have influenced the results. Second, the myocardial ischemic times in this study were 50-100 minutes, generally within the $\leq 90$ minute range where DN and HTK have both been seen to work well. Whereas multidose HTK has been used in clamp times up to 240 minutes with reasonable success, animal and human evidence tend to suggest that single-dose HTK may be increasingly associated with myocardial injury with clamp times $>120$ minutes. It is not yet known whether single-dose DN can provide reliable protection in adults with clamp times much longer than 90 minutes. $^{2}$

Finally, clinical assessment of perioperative myocardial protection is difficult at best. Perioperative cardiac isoenzyme levels have been famously difficult to relate to relevant clinical outcomes. Use of postoperative cardiac inotropes can be subjective and not a very sensitive measure of systolic or diastolic performance.

\footnotetext{
From the Division of Cardiothoracic Surgery, Department of Surgery, Duke University Medical Center, Durham, NC.

Disclosures: The author reported no conflicts of interest.

The Journal policy requires editors and reviewers to disclose conflicts of interest and to decline handling or reviewing manuscripts for which they may have a conflict of interest. The editors and reviewers of this article have no conflicts of interest.

Received for publication Dec 6, 2020; revisions received Dec 6, 2020; accepted for publication Dec 7, 2020; available ahead of print Dec 23, 2020.

Address for reprints: Donald D. Glower, MD, Division of Cardiothoracic Surgery, Department of Surgery, Duke University Medical Center, Box 3851 Duke University Medical Center, Durham, NC 27710 (E-mail: Glowe001@mc.duke.edu).

J Thorac Cardiovasc Surg 2022;164:e173 $0022-5223 / \$ 36.00$

Copyright (c) 2020 Published by Elsevier Inc. on behalf of The American Association for Thoracic Surgery

https://doi.org/10.1016/j.jtcvs.2020.12.047
}

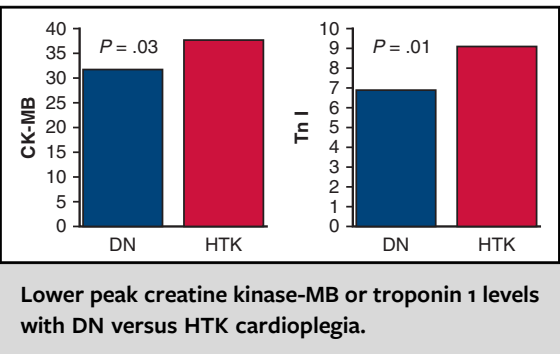

CENTRAL MESSAGE

Single-dose del Nido versus HTK cardioplegia in 456 propensitymatched patients undergoing minimally invasive cardiac surgery showed lower peak cardiac isoenzyme levels.

In most clinical practices, measurable adverse outcomes attributable to myocardial injury are infrequent, perhaps in the range of $<5 \%$ of cases. To detect a gross $50 \%$ improvement in adverse events, each study arm could require 400 patients or more. Clinical trials are very expensive and unlikely to occur unless sponsored by an industry likely to make millions of dollars from a positive outcome. Cardioplegia and myocardial protection are not very profitable industries at present. Thus, studies like that by Lee and colleagues ${ }^{1}$ are likely to be rare and limited to showing general safety of any 1 myocardial protection technique. We may always be dependent on animal investigations to point the way to potentially more effective myocardial protection strategies.

Although this retrospective study is not a prospective randomized trial, it provides some of the best detailed data to date showing that use of DN in MICS can be safe at 5090 minutes of clamp time. It remains difficult to say whether single-dose DN versus single-dose HTK is truly better in terms of myocardial protection up to 90 minutes of ischemia. Unlike multidose HTK, the safety of single or multidose $\mathrm{DN}$ beyond 90 minutes remains to be proven.

\section{References}

1. Lee CH, Kwon Y, Park SJ, Lee JW, Kim JB. Comparison of del Nido and histidine-tryptophan-ketoglutarate cardioplegic solutions in minimally invasive cardiac surgery. J Thorac Cardiovasc Surg. 2022;164:e161-71.

2. Ad N, Holmes SD, Massimiano PS, Rongione AJ, Fornaresio LM, Fitzgerald D The use of del Nido cardioplegia in adult cardiac surgery: a prospective randomized trial. J Thorac Cardiovasc Surg. 2018;155:1011-8. 